\title{
Price, Rachel. Planet/Cuba: ART, CULTURE, AND THE FUTURE OF THE ISLAND ${ }^{1}$
}

\author{
Renan Salmistraro \\ Universidade Estadual de Campinas \\ Campinas - Brasil
}

Publicado em novembro de 2015, Planet/Cuba: Art, Culture, and the Future of the Island oferece uma visão profundamente inovadora da arte e da cultura cubanas contemporâneas. Desde a Revolução de 1959, Cuba ocupou o imaginário mundial como um território fechado, condição agravada pelo embargo econômico de 1961, que isolou literalmente o país numa ilha em meio a um mar capitalista. A revolução, a oposição ao capitalismo americano e a relação com a antiga URSS contribuíram para sustentar o mito da excepcionalidade cubana, sob a imagem de uma ilha congelada e fixa, deslocada do mundo.

Porém, o retrato oferecido por Rachel Price (professora associada da Universidade de Princeton) apresenta um país que, longe de parar no tempo, esteve em contínua transformação. $\mathrm{Na}$ introdução "A treasure map for the present", ela descreve como o colapso da URSS em 1991 acrescentou àquela visão da ilha a imagem de uma terra arrasada, isolada pelo oceano e permeada por árvores, carros antigos, pouca tecnologia, escassez de alimentos e arquitetura destruída. Na verdade, para Price esse momento é o início de uma década distinta de todas as outras em Cuba, uma vez que o fim do apoio soviético impôs ao governo cubano a necessidade de encontrar novas diretrizes para o futuro, de repensar velhas ideologias e de abrir espaço a novos atores sociais.

Os anos finais do século XX, portanto, deram origem a uma nova realidade, que passou não só pela substituição do leninismo soviético, como pela superação do internacionalismo do governo de Fidel Castro. $\mathrm{O}$ aspecto épico da ascensão do governo revolucionário em 1959 atraiu a atenção mundial, espalhando expectativas que colocaram sobre a ilha obrigaçóes internacionais, fosse como país comunista, latino americano ou do terceiro mundo. Tais

1 Price, Rachel. Planet/Cuba: Art, Culture, and the Future of the Island. London: Verso Books, 2015, 256p. 
expectativas muitas vezes foram assumidas pelos próprios cubanos, como indica a autodenominação nos anos 1960 como "primeiro território livre das Américas". Mas, segundo Price, as dificuldades posteriores ao colapso dos países do leste impuseram ao governo e ao povo cubano a necessidade de pensar os problemas locais numa perspectiva nacionalista. A ascensão de Raúl Castro ao poder em 2008, no entanto, direcionou o nacionalismo dos anos 1990 a um processo de internacionalização, que passaria pela abertura da economia cubana à globalização.

Embora Price tenha concluído seu estudo antes da normalização das relaçóes entre Cuba e EUA em 17 de dezembro de 2014, a perspicácia demonstrada em suas análises permite perceber que uma mudança radical não só estava prestes a ocorrer, como se fazia absolutamente necessária. Com exímio conhecimento das transformaçóes sociais, políticas e econômicas em Cuba, Price explora a intersecção entre arte e ambiente, desconstruindo aquela imagem convencional de uma ilha separada do resto do mundo. Sua proposta é superar essa visão construída nos últimos cinquenta anos, de modo que o título não seja lido como uma oposiçâo Planet/Cuba, planeta ou Cuba, mas uma espécie de divisão pela qual as questôes globais encontram respaldo na sociedade cubana.

O estudo foca nas produções artísticas cubanas das últimas décadas abordando desde romances e poesias, até intervenções artísticas, arte digital e videogames como forma de arte -, com o intuito de demonstrar como as crises globais emergentes orientam a nova visão da realidade representada pelos artistas. Para Price, na arte cubana contemporânea, a preocupação particular com o país, lugar comum no imaginário cubano desde os anos 1990, coincide com as preocupaçóes presentes em outros lugares do globo. Assim suas análises são desenvolvidas em torno de problemas que ultrapassam as fronteiras de qualquer nação, como o desmatamento, o aquecimento global, a escassez de recursos naturais, as formas de organização do trabalho e a obsessão com a segurança.

A originalidade do estudo aparece logo nos capítulos iniciais, pela forma como neles são retomados arquétipos binários na arte cubana - como rizomas e árvores - a partir de uma perspectiva global. Os dois primeiros capítulos - "We Are Tired of Rhizomes" e "Marabusales" - abordam questôes ligadas à agricultura, à crise do meio ambiente e ao pensamento ecológico. Price descreve a substituição da imagem deleuziana do rizoma (utilizada para se referir à coletividade democrática) pelo símbolo mais estável da árvore. Esta superação envolveria a falência da economia baseada na indústria açucareira, procurando formas de lidar com as consequências da industrialização da agricultura, como a destruição das plantas nativas e o empobrecimento do solo.

Embora o governo de Fidel Castro tenha investido no reflorestamento, conseguindo recuperar mais de $30 \%$ do território, além de criar leis para 
regulamentar a exploração da natureza, a forte campanha pela adoção do modelo industrial soviético que, além de outras coisas, envolvia a industrialização da agricultura, permanece como um alerta quanto ao potencial de destruição da indústria emergente nesta nova fase de globalização. Por isso, os artistas cubanos reagem com hesitação às novas diretrizes adotadas para o desenvolvimento da ilha.

O marabú, planta não nativa que chegou a ocupar mais de $50 \%$ do território abandonado pela indústria açucareira, representa a reação paradoxal dos cubanos quanto ao futuro. A planta adquire um aspecto negativo conforme se espalha pelo território, contribuindo para destruir o que restou da vegetação nativa. Na obra Modelo de expansión: marabú, dos artistas Ernesto Oroza e Gean Moreno, o marabú não só indica a falência das políticas agrícolas e ecológicas, como escancara a crise ambiental e o enfraquecimento do sistema capitalista. Por outro lado, seu crescimento e disseminação são mais complexos, à medida que avança sob o território abandonado pelas usinas, devolvendo nitrogênio ao solo destruído pela monocultura.

A ambivalência da metáfora do marabú está em destruir os resquícios da Cuba açucareira que não prosperou, ao mesmo tempo em que prepara a terra para um futuro incerto. Mas a proposta de interpretação do imaginário cubano sob um aspecto global leva Price a analisar as incertezas em relação ao futuro como um fato característico da cultura contemporânea em geral. Essa perspectiva fica ainda mais evidente nos dois capítulos seguintes, que tratam da preocupação em torno da escassez dos recursos naturais.

Se o derretimento das geleiras polares é mais alarmante a todos os países que possuem fronteiras marítimas, no caso de uma ilha como Cuba esse fenômeno pode gerar expectativas desoladoras em relação ao futuro. No capítulo "Havana Under Water", Price traça as mudanças na abordagem de um velho tema cubano: o mar. Nos últimos tempos, o mar surge no imaginário cubano como uma imagem desagradável, indicadora de perigo. A água não só está envolvida nas mudanças climáticas, como carrega a poluição da vida urbana e industrial. Nas obras de arte, ela contribui para a construção de uma visão apocalítica do futuro, como no trabalho Tsunami, de Humberto Díaz, e no romance Habana Underguater, de Erick Mota.

A insegurança quanto ao futuro também reforça a preocupação com a escassez dos recursos naturais. Entre as maiores preocupaçóes dos governantes contemporâneos, inclusive cubanos, está a busca pela independência energética. Nesse aspecto, a água também está presente, uma vez que representa a última fronteira entre o homem e as principais reservas de petróleo, além de ser a metáfora mais adequada à representação de um fenômeno intrínseco ao capitalismo: a circulação (de mercadorias, capital e pessoas).

Sob essa perspectiva, Price discute com muita acuidade, no capítulo "Post-Panamax Energies", todo o processo de exploração do petróleo, desde 
sua regulamentação com base no sistema de posse do direito romano até as deliberaçóes mais recentes dos direitos de exploração. No entanto, este capítulo contribui à tese da autora (sobre a presença marcante dos problemas globais no imaginário cubano) quando reconhece que, embora as descobertas de petróleo náo sejam significativas em Cuba a ponto de mudar sua economia ou estrutura energética, a sua centralidade no mundo faz dele um tema constante na arte cubana contemporânea.

Após abordar a preocupação com as reservas de energia como um dos problemas mais recorrentes do mundo globalizado, Price volta-se a um dos temas que nas últimas décadas pareceu distinguir a Cuba comunista do resto do mundo capitalista: a relação entre trabalho, produtividade e tempo livre. $\mathrm{O}$ penúltimo capítulo, "Free Time", oferece uma análise fina de como questóes relativas à ocupação, ao desemprego, ao jogo e à falta de produtividade estão presentes no cotidiano da ilha. Enquanto na maioria dos países de capitalismo avançado o tempo livre é visto como antídoto ao trabalho, Price entende que a preocupação do Estado cubano voltada ao bem-estar social dedicou o trabalho estatal à subsistência, de modo que o tempo livre costuma ser direcionado a trabalhos mais lucrativos. Contudo, o avanço da economia informal não é interpretado como um aspecto particular da sociedade cubana, uma vez que também está presente na maioria dos países capitalistas.

Além do mercado informal, outro aspecto da relação entre o homem contemporâneo e o ócio, que repercute em Cuba, é o modo como a cultura de massa modela a construção da subjetividade a partir do tempo livre e do jogo. Uma parte significativa do capítulo é dedicada à abordagem da relação entre a indústria dos games e a colonização do tempo livre, o que parece ser um tema de grande interesse da autora. Embora o acesso à internet ainda seja um problema em Cuba, por ser demasiadamente lento e escasso, ele faz parte da nova política de Raúl Castro de "eliminar proibiçóes", que também liberou a venda de computadores pessoais, celulares e televisores. Para Price, tal abertura contribuiu para a progressiva distinção entre a vida cotidiana na ilha e a "retórica estatal" dos últimos cinquenta anos. O grande responsável por esta transformação seria o acesso às produçóes audiovisuais estrangeiras, de grande conhecimento especialmente por parte dos artistas cubanos.

A ênfase no desenvolvimento dos recursos tecnológicos engloba inclusive a obsessão do Estado moderno com o problema da segurança. Nessa linha, Price destaca no último capítulo, "Surveillance and Detail in the Era of Camouflage", obras performáticas, como da artista Tania Bruguera, e experimentais, como a adaptaçáo do modelo de prisão descrito por Jeremy Bentham (pan-óptico) para o videogame, realizada por Rodolfo Peraza em Jailhead.com. A abordagem do aperfeiçoamento de um sistema de segurança cada vez mais invasivo - que tem a tecnologia como principal aliada -, a partir de artistas que adotam recursos tecnológicos como estratégia de representação, 
foi um grande lampejo da autora para defender que as formas de vigilância e controle não estão encerradas nos centros de correção ou nas instituições, mas sim disseminadas pelos lugares mais diversos da vida cotidiana.

Ao colocar no horizonte da arte cubana os problemas globais, Price consegue desmistificar algumas consequências do isolamento político das últimas décadas, como a sensação de que Cuba é uma ilha-planeta com uma realidade própria. Apesar de ter que lidar com os problemas globais respeitando as particularidades de seu processo histórico, a Cuba de Price passa por múltiplas transformaçóes que se confundem com os dilemas do mundo atual. Dessa forma, a promessa presente no título de discutir o futuro da ilha ( “... and the Future of the Island") não pode ser entendida literalmente, uma vez que as expectativas quanto ao futuro na ilha são tão incertas, duvidosas e angustiantes quanto em qualquer outro lugar do planeta. A abordagem dos impactos das transformaçóes globais na ilha definitivamente recoloca Cuba numa perspectiva global, menos como ilha-planeta e mais como país.

Renan Salmistraro é Doutorando em Teoria e História Literária na UNICAMP. E-mail: renansalmistraro@gmail.com 